\title{
Impactos sobre a economia brasileira ocasionados pela abertura comercial ocorrida na década de 90 nos setores têxteis e de artigos de vestuário: uma análise de equilíbrio \\ geral $^{1}$
}

\author{
Andressa Rodrigues Pavão ${ }^{2}$ \\ Silvia Kanadani Campos ${ }^{3}$
}

\begin{abstract}
Resumo: O objetivo deste trabalho foi analisar o efeito de uma queda de preços de 20\% em têxteis e artigos de vestuário, no período entre 1996 e 2007, paralelamente ao aumento das tarifas de importação de 17,8\% em artigos de vestuário (política implementada em 2007). Foi utilizado um modelo de equilíbrio geral com base em dados da matriz insumo-produto de 1996 (IBGE). Observou-se que a Indústria têxtil foi a mais diretamente penalizada, sobretudo na produção e geração de empregos. A indústria de vestuário vivenciou uma redução de custos de sua principal matéria-prima, o que, no curto prazo, beneficiou sua produção. Embora no curto prazo os efeitos para a economia brasileira tenham sido de modo geral benéficos, com o aumento do emprego e do consumo das famílias, no longo prazo, houve queda dos salários e do consumo das mesmas. Além disso, tanto no curto quanto no longo prazo houve queda do PIB real.
\end{abstract}

Palavras-chave: tarifas; têxteis; equilíbrio geral.

\section{Impacts on the Brazilian economy caused by the commercial openness occurred in the 9o's in the textile and clothing sector: $a$ general equilibrium study}

\footnotetext{
Abstract: The objective of this work was to analyze the effect of a $20 \%$ collapse of prices in textile and clothing products, in the period between 1996 and 2007, parallel to the increasing of the tariffs of importation of $17,8 \%$ in clothing products (policy

1 Agradecimentos especiais ao Prof. Dr. Joaquim Bento de Souza Ferreira Filho do Departamento de Economia, Sociologia e Administração Rural da Esalq/USP pelas valiosas contribuições e aos pareceristas da Revista de Economia pelas sugestões para o aperfeiçoamento do trabalho.

2 Doutoranda, Economia Aplicada, Esalq/USP. Bolsista do CNPq. e-mail: arpavao@esalq.usp.br

3 Doutoranda, Economia Aplicada, Esalq/USP. Bolsista do CNPq. e-mail: kanadani@esalq.usp.br
} 
implemented in 2007). A general equilibrium model was used based in data from the input-product matrix of 1996 (IBGE). It was observed that the textile industry was the most directly punished, especially in the production and generation of employments. The clothes industry has lived a reduction of costs of its principal raw material, which benefitted its production in the short-run. Although in the short-run the effects for Brazilian economy have been in general beneficial, with the increasing of the employment and the consumption of the families, in the longrun there was a fall of the wages and the consumption of the same ones. Besides, there was fall of real GDP in the short-run as in the long-run.

Keywords: tariffs; textile; general equilibrium model.

Resumen $^{4}$ : El objetivo de este trabajo fue analizar el efecto de una caída de precios de $20 \%$ en tejidos y artículos de vestuario, en el periodo entre 1996 y 2007, paralelamente al aumento de las tarifas de importación de 17,8\% en artículos de vestuario (política implementada en 2007). Fue utilizado un modelo de equilibrio general con base en los datos de la matriz insumo-producto de 1996(IBGE). Se observó que la industria textil fue penalizada más directamente, sobre todo en la producción y generación de empleos. La industria de vestuario vivió una reducción de costos en su principal materia prima, lo que en el corto plazo benefició su producción. Aunque en el corto plazo los efectos para la economia brasileña hayan sido beneficiosos de manera general, con el aumento de empleo y consumo de las familias, en el largo plazo hubo una caída de los salarios y del consumo de las mismas. Además, tanto en el corto como en el largo plazo, hubo estancamiento del PIB real.

Palabras-clave: Tarifas; Textiles; Equilibrio General.

Classificação JEL: D58 General Equilibrium and Disequilibrium- Computable and Other Applied General Equilibrium Models

\section{Introdução}

A indústria têxtil e de vestuário do Brasil, assim como em diversos países, foi a base do processo de industrialização. Sua importância no produto interno bruto (PIB) industrial era bastante elevada até a década de 1950, quando então, as indústrias de transformação e automobilística cresceram, ofuscando sua importância econômica. De acordo com Garcia (1994), no período da segunda guerra mundial, o país chegou a ser o segundo maior produtor mundial de tecidos.

A participação desses setores no PIB era de 2,63\% em 1996, com base em dados da Matriz de Insumo Produto divulgados pelo IBGE. Todavia a indústria têxtil e de vestuário possui grande importância social devido aos números de empregos gerados. 
Em 2007, o setor têxtil como um todo era composto por, aproximadamente, 26.500 empresas (23.276 de confecções, 2.511 malharias, 417 de fiação e 596 de tecelagem) e empregava, diretamente, 1.500 .000 trabalhadores, o que o classificava entre os primeiros lugares no conjunto da indústria de transformação, em termos de geração de emprego (IEMI 2008).

Especificamente em relação ao setor de vestuário, ressalta-se que até 20050 Brasil era o sexto maior produtor, com 1,062 milhões de toneladas por ano, o que representa 2,9\% da produção mundial. Os líderes eram China e Hong Kong (13,625 milhões), Índia (2,571 milhões), Paquistão (1,255 milhão), México (1,227 milhão) e Turquia (1,215 milhão) (IEMI 2007).

Contudo, o número de empresas vem reduzindo nos últimos anos devido à quebra de empresas ineficientes e fusões de empresas maiores. Dessa forma, o número de empregos também sofre forte redução, visto que as pequenas empresas desse setor são as que mais empregam em relação ao faturamento obtido.

A abertura comercial iniciada na década de 1990 foi de grande importância para entrada de máquinas e equipamentos no país, mas não foi suficiente para a modernização do setor. Com a grande entrada de produtos asiáticos muitos empreendedores do setor ficaram receosos de investirem, determinando o fechamento de dezenas de estabelecimentos e gerando a demissão de muitos funcionários entre 1990 e 2000. Dados do IEMI (2007) mostram um decréscimo de 67,94\% no número de fiações, 70,69\% no número de tecelagens e 11,80\% no número de malharias entre os anos de 1991 e 2001.

A aquisição de máquinas e equipamentos pelo setor, bem como o aumento das importações estão diretamente relacionados com as tarifas de importação impostas ao setor têxtil e de vestuário no Brasil, sendo estas fundamentais para incentivar sua modernização. Ainda assim, conforme Prochnik (2003: 61):

(...) em praticamente todos os países, a cadeia produtiva têxtil/confecções (CTC) conta com maior proteção tarifária do que o conjunto da indústria. A proteção à CTC é proporcionalmente maior nos países desenvolvidos, onde, curiosamente, a participação da CTC na produção e comércio é menor.

Esta redução também foi creditada às dificuldades que o setor apresentou em função da condução da política econômica de controle da inflação inercial e de ajuste cambial. Se por um lado a sobrevalorização da moeda facilita a importação de máquinas, por outro prejudica no curto prazo as empresas exportadoras que passam a receber menos pela sua mercadoria tendo que deixar o mercado ou se tornarem mais competitivas para conseguirem produzir com um custo menor.

De fato, a abertura comercial do país, com suas consequentes quedas nas 
tarifas de importação e a manutenção do câmbio sobrevalorizado após a adoção do Plano Real, trouxeram acentuadas mudanças no mercado nacional (Campos \& Campos 2004). De acordo com informações do CNI/ABIT - Confederação Nacional das Indústrias/ Associação Brasileira da Indústria Têxtil e de Confecção (2000: 7):

A abertura da economia brasileira na década de 1990 e o acirramento da competição mundial, com a consolidação de diversos produtores de baixo custo, basicamente os asiáticos (...), promoveram radical transformação do setor (...). As empresas mais atingidas foram as firmas de menor porte, com atuação exclusiva no mercado interno e baixo nível tecnológico. Dentro da cadeia têxtil, os setores mais atingidos pela concorrência externa foram o produtor de fibras de algodão, o de fios e tecidos sintéticos e o de confecções.

O Brasil apesar de ser competitivo em algodão, fiação e tecelagem deixou de lado a inovação em produtos à base de fibras sintéticas e artificiais. Ressaltase que a quase totalidade dos investimentos realizados no país na década de 1990 beneficiou a cadeia de têxteis naturais (algodão), praticamente, não contemplando a cadeia sintética ou de origem química (CNI/ ABIT 2000).

Visto que o segmento produtor de fibras artificiais e sintéticas exige constantes investimentos em pesquisa e modernização para aumentar a eficácia de suas operações industriais, reduzir seus custos e assegurar a sua competitividade internacional, o país ficou ineficiente neste setor.

Cabe ressaltar que a proteção ao setor vestuário, geralmente, é maior que a proteção ao setor têxtil, o que introduz um viés na estrutura produtiva dos países em desenvolvimento, pois favorece relativamente mais a produção de bens menos refinados.

Outro grande problema enfrentado é que o país vem seguindo tendência contrária ao mercado mundial; enquanto o consumo mundial de fibras naturais vem decrescendo, a produção nacional está aumentando e embora o consumo mundial de fibras sintéticas esteja aumentando, a produção brasileira está reduzindo. Isso pode justificar o declínio das exportações e o aumento das importações brasileiras de confecções enquanto que o comércio internacional de têxteis cresce acima da média dos outros produtos.

Todavia a maior dificuldade que o setor enfrenta é a queda real no preço do produto (Figura 1) pressionada, principalmente, pelo baixo custo de produção dos asiáticos e o crescimento da oferta mundial acima da demanda. Aliados a esses fatores externos encontram-se problemas internos que dificultaram o crescimento e a modernização da produção nacional. Dentre eles estão a abertura comercial, a recessão, a elevada taxa de juros e restrições ao crédito, os quais contribuíram para o elevado grau de obsolescência do parque têxtil nacional, onde o setor de sintéticos foi o mais atingindo. 


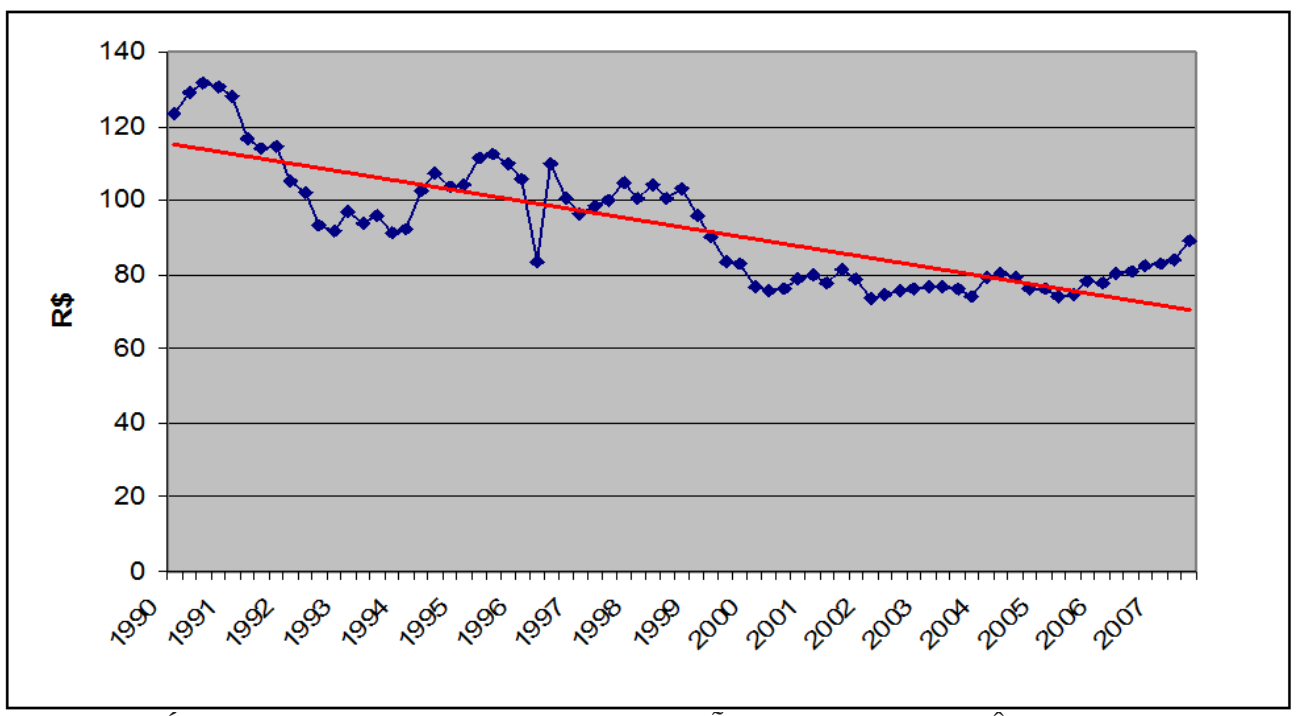

FIGURA 1- ÍNDICE DE PREÇOS DAS IMPORTAÇÕES POR SETOR: TÊXTIL NO PERÍODO ENTRE 1990 E 2007 (MÉDIA 1996 = 100).

FONTE: Ipeadata (2007).

Dessa forma, o país está perdendo mercado num setor de grande importância social na geração de empregos. Todavia, resta analisar qual a melhor política a ser adotada a fim de proteger o setor e seus empregados, sem prejuízo ao consumidor.

Por sua vocação, de gerar empregos e de criar bases para o desenvolvimento industrial, é natural que os estudos que envolvam as políticas direcionadas a reduzir as disparidades sociais, gerando emprego e renda, tratem deste setor com especial atenção. Diante dessas preocupações, este trabalho pretende verificar por meio de um modelo de equilíbrio geral qual o impacto para a economia de uma queda de $20 \%$ nos preços mundiais dos produtos da indústria de têxtil e de vestuário.

Sendo essa queda significativa para a geração de empregos, este trabalho propõe-se a investigar o efeito do aumento de aproximadamente $17,8 \%^{5}$ (no período analisado) nas tarifas de importação de artigos de vestuário para a economia brasileira.

De fato, de acordo com Morelli (2008) o governo decidiu elevar a tarifa de importação de calçados e vestuário de 20\% para 35\%, de modo a beneficiar a indústria nacional desses dois setores, prejudicada com a valorização do câmbio e aumento das importações, principalmente de países asiáticos. 


\section{Metodologia}

\subsection{Referencial Teórico}

Analisar impactos econômicos e no bem-estar proveniente de acordos comerciais e liberalizações tarifárias consiste em uma prática comum em trabalhos que utilizam modelos computáveis de equilíbrio geral.

Cavalcante e Mercenier (1999) avaliam os ganhos do Mercosul mediante a redução do nível tarifário entre 1992 e 1996, ressaltando que a base de dados utilizada foi de 1992. O resultado do trabalho é consistente com o encontrado por Brown, Deardoff e Stern (1994) no qual os países menores obtêm maiores ganhos de bem-estar com acordos de livre comércio.

Domingues e Haddad (2006) apesar de utilizarem o modelo Sparta, mais simples que o GTAP, comumente utilizado em trabalhos que envolvem comércio entre vários países, obtêm resultado favorável à ideia de que a liberalização tarifária contribui para o crescimento do PIB e a geração de superávit comercial no longo prazo.

Estes trabalhos que utilizam modelos de equilíbrio geral consistem numa forma de aplicar o que há muito tempo vem sendo observado pela teoria sobre economia internacional. Em Krugman e Obstfeld (2005), observa-se que desde a época de Adam Smith os economistas têm defendido o livre comércio, acreditando que este evita as perdas de eficiência associadas à proteção. Os argumentos a favor do livre comércio apontam que uma tarifa de importação gera uma perda líquida para a economia, que ocorre ao destorcer os incentivos econômicos tanto de produtores como de consumidores, gerando perda de bem-estar.

No caso de um país capaz de afetar os preços dos exportadores estrangeiros, uma tarifa diminui o preço das importações e, dessa forma, beneficia os termos de troca. Se os benefícios proporcionados pela tarifa superarem seus custos, temos um argumento a favor da tarifa. Porém, mesmo se fosse a princípio vantajoso uma tarifa de importação para um país, este estaria sujeito a sofrer retaliações comerciais de outros países no longo prazo.

Todavia, apesar dos fortes argumentos a favor da liberalização comercial, o que se observa é que quase todos os países utilizam algum tipo de intervenção, seja tarifas de importação, ou subsídios a exportação.

Com a finalidade de desenvolver ou mesmo proteger alguns setores econômicos considerados importantes, muitos países utilizaram e utilizam o argumento da indústria nascente para conceder tarifas ou cotas de importação temporária a setores específicos até que estejam aptos a competirem com seus concorrentes consolidados no mercado. Os Estados Unidos e a 
Alemanha mantinham alíquotas tarifárias elevadas sobre as manufaturas, o Japão manteve controles de importação até a década de 1970, porém o Brasil utilizou políticas de substituição de importação por muitas décadas e houve setores, como o naval, que não sobreviveram sem os benefícios do governo.

Para verificar os impactos econômicos na queda mundial dos preços dos produtos têxteis, bem como a abertura comercial do Brasil na década de 1990, foi utilizado o modelo de equilíbrio geral computável (EGC) MINIMAL, originalmente construído por Horridge (2001) com dados para a economia australiana. O MINIMAL, todavia, foi adaptado para os dados da economia brasileira e a versão brasileira é descrita por Hasegawa et al. (2006). O MINIMAL omite algumas características presentes em modelos de EGC maiores, mas mantém intactas as ideias principais (Hasegawa et al. 2006).

Apesar das limitações próprias da metodologia empregada, este modelo possibilita obter um conjunto significativo de resultados indicativos das repercussões setoriais analisando apenas o Brasil e o resto do mundo. Os principais pressupostos são: não distingue modalidades de impostos, considerando apenas dois (um sobre a produção, outro sobre a importação); os diferentes usuários de cada bem pagam a mesma alíquota de imposto; o mercado encontra-se em competição perfeita ${ }^{6}$ com as famílias consumindo toda a renda obtida e desse modo do lado da produção o custo do produto corresponde ao seu preço, o que impede ganhos de lucro puro; os agentes são tomadores de preços; cada commodity é produzida por um único setor.

A estrutura de produção do modelo é formada inicialmente por uma função Leontief entre as diferentes matérias-primas necessárias à produção de cada setor e os fatores primários, que no modelo são apenas trabalho e capital, ou seja, os insumos são demandados em proporção direta à produção. Num segundo nível, após verificar a quantidade de matérias-primas e de fatores primários de produção necessários, é utilizada uma função de elasticidade de substituição constante (CES), com base nos preços relativos de fontes nacionais e estrangeiras para estabelecer as proporções entre domésticos/ importados, como pode ser observado na Figura 2.

6 Apesar de Gurgel e Campos (2006) apresentarem resultados de maior intensidade no bem-estar quando economias de escala e competição imperfeita estão presentes no modelo, estes autores especificam que setores como agropecuária, têxteis, calçados e de serviços apresentam estruturas de competição mais próximas da competição perfeita, por isso a opção pela utilização de modelos tradicionais de competição perfeita. 


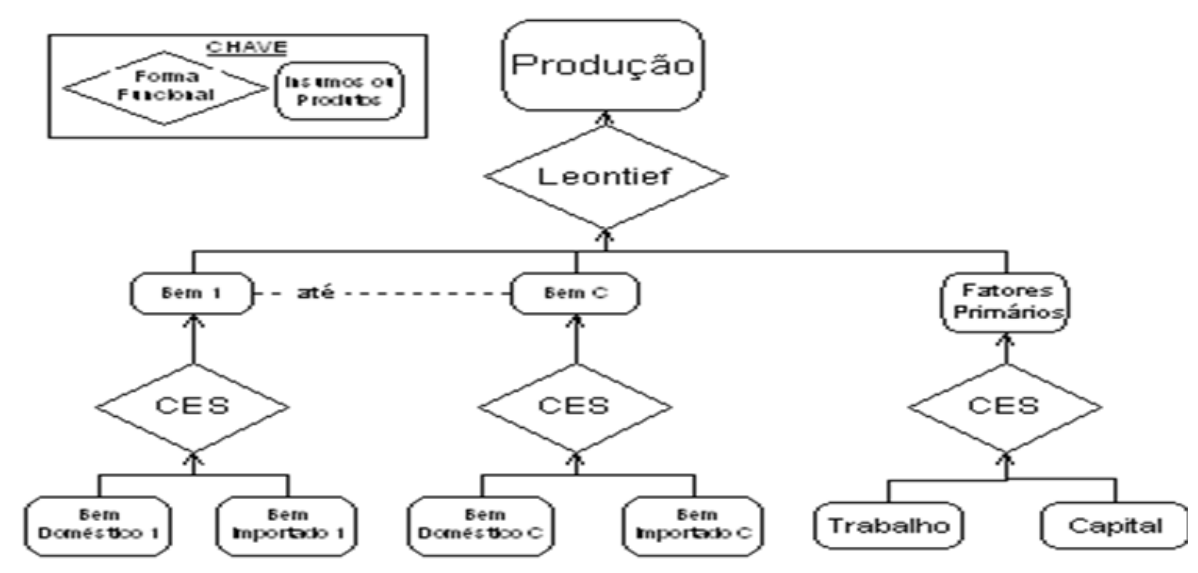

FIGURA 2 - ESTRUTURA DE PRODUÇÃO ANINHADA FONTE: Hasegawa et al. , 2006.

Pelo lado da demanda das famílias, o modelo considera unidades maximizadoras de utilidade. Pressupõe-se que a utilidade é gerada por uma função agregadora Cobb-Douglas entre os diferentes produtos demandados pelas famílias. Assim como na estrutura de produção, em um segundo nível há uma elasticidade de substituição constante (CES) entre a demanda em particular de cada produto para produto importado ou doméstico (Figura 3).

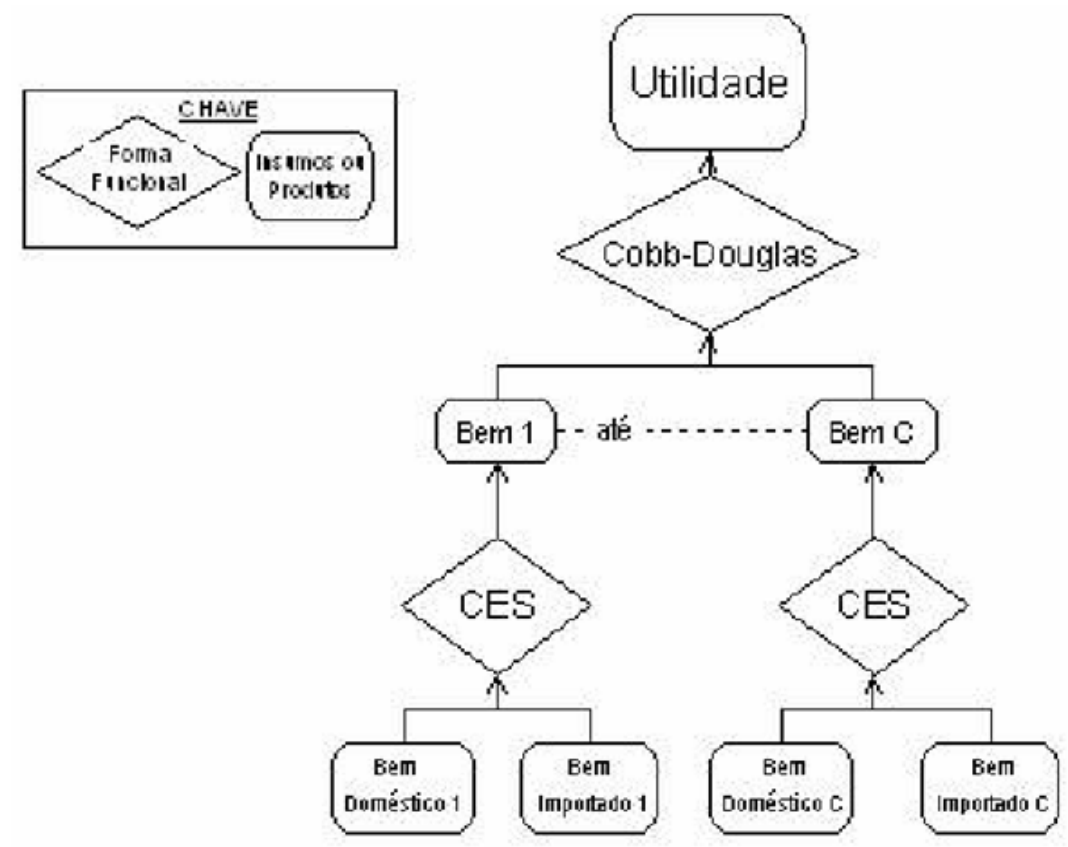

FIGURA 3 - ESTRUTURA DE DEMANDA DO CONSUMIDOR ANINHADA FONTE: Hasegawa et al. 2006. 


\subsection{Agregação dos dados}

A base de dado utilizada no modelo é a matriz de insumo produto (MIP) brasileira de 1996, uma vez que este trabalho pretende avaliar os impactos sobre a economia brasileira ocasionados pela abertura comercial ocorrida na década de 1990. Tal economia possui 42 setores e muitos deles não têm uma relação direta com o setor de indústria têxtil e de artigos de vestuário. Dessa forma é feita uma agregação dos setores, analisando separadamente apenas aqueles que interessam à pesquisa.

O critério utilizado para a agregação foi verificar a importância (em termos de participação) dos setores na formação dos custos (fornecedores de insumo) e da receita (consumidores) do setor de indústria têxtil e de artigos de vestuário. A agregação resultou em 12 setores e 4 demandantes finais totalizando 16 usuários (Tabela 1).

TABELA 1. AGREGAÇÃO DOS SETORES COM BASE NAS PARTICIPAÇÕES (\%) DE CUSTO E RECEITA DA INDÚSTRIA TÊXTIL E DO SETOR DE VESTUÚRIO.

\begin{tabular}{|c|c|c|c|c|c|}
\hline \multirow[b]{2}{*}{ Setores Agregados } & \multirow[b]{2}{*}{ Composição } & \multicolumn{2}{|c|}{ Receita } & \multicolumn{2}{|c|}{ Custos } \\
\hline & & $\begin{array}{l}\text { Indústria } \\
\text { Têxtil (\%) }\end{array}$ & $\begin{array}{c}\text { Artigos de } \\
\text { Vestuário }\end{array}$ & $\begin{array}{l}\text { Indústria } \\
\text { Têxtil (\%) }\end{array}$ & $\begin{array}{l}\text { Artigos de } \\
\text { Vestuánio }\end{array}$ \\
\hline Agropecuáıia & Agropecuária & 0.92 & 0.00 & 7.00 & 0.10 \\
\hline \multirow{3}{*}{ Mineração } & Extrativa Mineral & 0.08 & 0.10 & 0.00 & 0.00 \\
\hline & Extração de Petróleo e Gás & 0.00 & 0.00 & 0.00 & 0.00 \\
\hline & Minerais não Ferrosos & 0.00 & 0.00 & 0.00 & 0.00 \\
\hline Subtotal Mineração & & 1.00 & 0.10 & 0.00 & 0.00 \\
\hline \multirow{8}{*}{ Manufaturado } & Minerais não metálicos & 0.06 & 0.00 & 0.00 & 0.00 \\
\hline & Siderurgia & 0.00 & 0.10 & 0.00 & 0.00 \\
\hline & Outros Metalúrgicos & 0.03 & 0.00 & 0.60 & 0.70 \\
\hline & Automóveis & 0.34 & 0.20 & 0.00 & 0.00 \\
\hline & Outros Veículos e Peças & 0.38 & 0.00 & 0.00 & 0.00 \\
\hline & Papel e Gráfica & 0.24 & 0.10 & 1.00 & 1.50 \\
\hline & Indústria de Borracha & 1.49 & 0.00 & 0.40 & 0.30 \\
\hline & Indústria Diversas & 0.64 & 0.00 & 0.40 & 0.60 \\
\hline Subtotal Manufaturado & & 3.18 & 0.40 & 2.40 & 3.10 \\
\hline Indústria têxtil & Indústria Têxtil & 37.04 & 0.00 & 58.20 & 77.40 \\
\hline Artigos de Vestuário & Artigos de Vestuário & 23.06 & 0.00 & 0.00 & 0.10 \\
\hline \multirow{4}{*}{ Capital fixo } & Máquinas e Tratores & 0.20 & 0.10 & 2.50 & 0.50 \\
\hline & Material Elétrico & 0.05 & 0.00 & 0.00 & 0.00 \\
\hline & Equipamentos Eletrônicos & 0.07 & 0.00 & 0.10 & 0.00 \\
\hline & Madeira e Mobiliário & 0.79 & 0.00 & 0.10 & 0.10 \\
\hline Subtotal Capital Fixo & & 1.11 & 0.10 & 2.70 & 0.60 \\
\hline Refino de petróleo & Refino de Petróleo & 0.18 & 0.10 & 1.30 & 0.30 \\
\hline \multirow{4}{*}{ Indústria Química } & Elementos Químicos & 0.03 & 0.00 & 0.50 & 0.00 \\
\hline & Quimicos Diversos & 0.12 & 0.00 & 12.70 & 1.20 \\
\hline & Farmácia e Perfumaria & 0.04 & 0.00 & 0.00 & 0.00 \\
\hline & Artigos Plásticos & 0.53 & 0.00 & 1.10 & 1.20 \\
\hline Subtotal Indústria Química & & 0.71 & 0.00 & 14.30 & 2.40 \\
\hline \multirow{8}{*}{ Agroindústria } & Fabricação de Calçados & 0.64 & 0.00 & 0.10 & 1.30 \\
\hline & Indústria de Café & 0.09 & 0.00 & 0.00 & 0.00 \\
\hline & Beneficiamento Vegetal & 0.46 & 0.00 & 0.10 & 0.00 \\
\hline & Indústria de Abate de Animais & 0.05 & 0.00 & 0.00 & 0.00 \\
\hline & Indústria de Laticínio & 0.02 & 0.00 & 0.00 & 0.00 \\
\hline & Indústria de Açúcar & 1.15 & 0.00 & 0.00 & 0.00 \\
\hline & Fabricação de Óleos Vegetais & 1.02 & 0.00 & 0.00 & 0.00 \\
\hline & Outros Produtos Alimentares & 0.16 & 0.00 & 0.00 & 0.00 \\
\hline Subtotal Agroindústria & & 3.58 & 0.00 & 0.20 & 1.30 \\
\hline Construção Civil & Construção Civil & 0.08 & 0.10 & 0.00 & 0.20 \\
\hline \multirow{2}{*}{ Comércio e transporte } & 34 Comércio & 0.45 & 0.00 & 5.70 & 6.20 \\
\hline & 35 Transportes & 1.25 & 0.00 & 1.60 & 1.20 \\
\hline Subtotal Comércio e Transporte & & 1.70 & 0.00 & 7.30 & 7.40 \\
\hline
\end{tabular}


TABELA 1. AGREGAÇÃO DOS SETORES COM BASE NAS PARTICIPAÇÕES (\%) DE CUSTO E RECEITA DA INDÚSTRIA TÊXTIL E DO SETOR DE VESTUÁRIO.

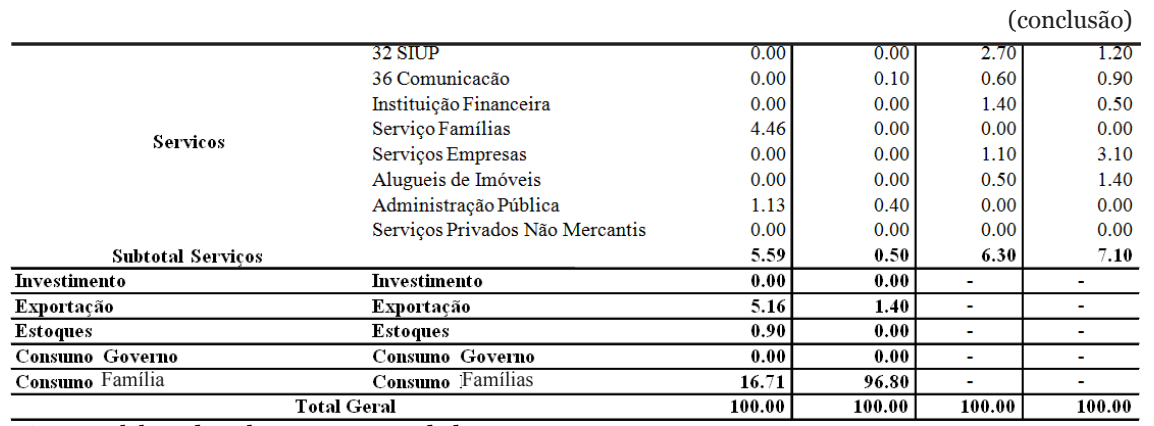

FONTE: Elaborado pelos autores com dados na MIP 96

Observa-se que a indústria têxtil é o principal fornecedor de insumos para o setor de artigos de vestuário, sendo sua participação nos custos totais do setor de $77 \%$. Além disso, ela é responsável por $58 \%$ dos custos do próprio setor têxtil, isso porque nela está incluso tanto a produção de tecidos como de fios utilizados em sua produção. Outros setores significativos incluem o refino de petróleo, a agropecuária, serviços, comércio e transporte e indústria química. No que se refere às receitas, destaca-se o Consumo das Famílias que é responsável por $17 \%$ da receita da indústria têxtil e $97 \%$ dos artigos de vestuário. A receita da indústria têxtil provém ainda da própria indústria têxtil (37\%) e dos artigos de vestuário (23\%).

\subsection{Elasticidades utilizadas}

Considerando a agregação realizada pela pesquisa as elasticidades de Armington, de demanda por exportações e de substitubilidade entre fatores primários também foram agregadas e ponderadas segundo o peso do setor.

Os valores das elasticidades (de substituição) de Armington foram obtidos de Tourinho et al. (2003), sendo que para as elasticidades de demanda por exportações fez-se uso dos valores de Domingues (2002) e para elasticidade de substituição dos valores primários, consideramos o valor utilizado por Annabi et al. (2005), que foi de 1.2 para todos os setores. Os valores de todas as elasticidades utilizadas no modelo estão apresentados na Tabela 2. 
TABELA 2. ELASTICIDADES UTILIZADAS NO MODELO

\begin{tabular}{|c|c|c|c|}
\hline Setores & $\begin{array}{l}\text { Elasticidade de } \\
\text { Armington* }\end{array}$ & $\begin{array}{c}\text { Elasticidade } \\
\text { demanda das } \\
\text { exportações }\end{array}$ & $\begin{array}{l}\text { Elasticidade } \\
\text { demanda dos } \\
\text { fatores } \\
\text { primários }\end{array}$ \\
\hline Agropecuária & 1,91 & $3^{* * *}$ & 1,2 \\
\hline Mineração & 0,86 & 1,45 & 1,2 \\
\hline Manufatura & 1,81 & 1,27 & 1,2 \\
\hline Capital fixo & 0,99 & 1,54 & 1,2 \\
\hline Química & 0,93 & 2,40 & 1,2 \\
\hline Indústria Têxtil & 2,34 & 4,54 & 1,2 \\
\hline $\begin{array}{l}\text { Ind. Artigos } \\
\text { vestuário }\end{array}$ & 2,20 & 0,40 & 1,2 \\
\hline Refino Petróleo & 0,18 & 5,09 & 1,2 \\
\hline Agroindústria & 1,89 & 1,19 & 1,2 \\
\hline Com. Transp. & 1,57 & 6,39 & 1,2 \\
\hline Const. Civil & 0,9 & 1,04 & 1,2 \\
\hline Serviços & 1,1 & 2,11 & 1,2 \\
\hline
\end{tabular}

FONTE: *Tourinho et al. (2003), ${ }^{* *}$ Domingues (2002), ${ }^{* * *}$ valores estabelicidos pelas autoras e ****Annabi et al. (2005).

É importante ressaltar que os resultados dos modelos de EGC são potencialmente sensíveis aos pressupostos adotados, sobretudo no que se refere aos valores das elasticidades. Assim, o impacto da variação dos preços internacionais será maior sobre o setor têxtil em relação a vestuário, uma vez que sua elasticidade de demanda é consideravelmente maior.

Para a agropecuária foi estabelecido o valor 3 para elasticidade de demanda das exportações por considerar que este já é um valor demasiadamente alto. $\mathrm{O}$ valor da elasticidade da demanda por exportações está relacionado à hipótese assumida quanto ao tamanho econômico do país no comércio internacional. Como o Brasil é considerado um grande produtor em muitas commoditties agropecuárias, este é capaz de influenciar os preços internacionais e deve-se, portanto, utilizar elasticidade-preço finita.

\subsection{Cenário para o choque: simulação da redução de pre- ços internacionais (têxteis e artigos de vestuário) e au- mento das tarifas de importaçôes (artigos de vestuário)}

O choque dado ao modelo considerou tanto a redução dos preços mundiais de têxteis, o que vem ocorrendo desde a década de 1990, com a desregulamentação dos mercados, quanto o aumento da tarifa de importação sobre artigos de vestuário, o que está sendo implementado pelo governo brasileiro desde 2007.

Foram feitos dois cenários de curto prazo e um de longo prazo. No primeiro cenário de curto prazo, considerou-se uma queda de $20 \%$ do preço mundial associada a um aumento de 17,8\% sobre as tarifas de importação de artigos de vestuário. 
Entre 1996 e 2007 o preço mundial de têxteis caiu aproximadamente 20\% e em 2007 o governo brasileiro lançou uma proposta de aumento das tarifas de $20 \%$ para $35 \%$, o que corresponde a um aumento de $17,8 \%$ quando se considera o período compreendido entre 1996 e 2007. Embora a queda de preço tenha ocorrido especificamente com artigos têxteis, considera-se a mesma queda para artigos de vestuário, uma vez que na análise de preços, têxteis incluem artigos de vestuário.

No segundo cenário de curto prazo, objetivou-se obter o valor da tarifa de importação que mantém constante a quantidade importada de artigos de vestuário, quando se tem uma redução de $20 \%$ dos preços mundiais de artigos têxteis e artigos de vestuário. Ressalta-se que o objetivo era manter zerada apenas a variação na quantidade importada de artigos de vestuário porque os artigos têxteis entram como matéria-prima na produção de roupas.

O choque de longo prazo foi similar ao primeiro choque de curto prazo, entretanto, alterou-se a determinação das variáveis exógenas. O valor do choque da redução dos preços mundiais foi baseado nos dados do Ipeadata, em que se observa que desde 1996 os preços vêm sofrendo tendência a quedas, sendo que em 2007 essa diferença atingiu em torno de $20 \%$.

O valor do choque de aumento das tarifas foi calculado com base nas tarifas vigentes observadas na MIP de 1996. Dessa forma foi calculado o quanto de tarifa de importação existia e verificou-se que faltava 17,8\% para atingir os $35 \%$ determinados pelo governo em 2007.

\subsection{Fechamento do modelo}

Os modelos de EGC geralmente possuem mais variáveis do que equações, tornando necessário determinar variáveis exógenas, ou seja, que serão determinadas fora do modelo. Este é o chamado "fechamento do modelo", sendo que o número de variáveis endógenas deve ser igual ao número de equações. A escolha dessas variáveis varia de acordo com a escola de pensamento do pesquisado e os objetivos da pesquisa.

O fechamento está associado ao período de tempo necessário para que as variáveis econômicas se ajustem ao novo equilíbrio. Neste estudo específico, três tipos de fechamentos foram considerados: o de curto prazo refletindo a queda de $20 \%$ dos preços mundiais de têxteis e artigos de vestuário e um aumento de $17,8 \%$ das tarifas de importação de vestuário (Tabela 3); outro de curto prazo que simula a obtenção da tarifa de importação que manteria constante a quantidade importada de artigos de vestuário; e um de longo prazo (Tabela 4), que também considera a queda de $20 \%$ dos preços mundiais e um aumento de $17,8 \%$ das tarifas de importação. Cabe ressaltar que a definição de curto e longo prazo é arbitrária, sendo que não se pode determinar o número de anos para cada um dos períodos em análise. 
TABELA 3. FECHAMENTO DAS SIMULAÇÕES DE CURTO PRAZO

\begin{tabular}{ll}
\hline \multicolumn{1}{c}{ Variáveis Exógenas } & \multicolumn{1}{c}{ Descrição } \\
\hline Phi & Taxa de Câmbio (R\$/US\$) \\
Realwage & Salário real \\
x1cap & Estoques de Capital corrente \\
DelB & Balança comercial/PIB \\
X_s(COM, "Government”) & Demanda do Governo \\
a1prim & Variação Técnica no Uso dos Fatores de \\
& Produção \\
Pworld & Preços Mundiais \\
f4q & Deslocador da Demanda por Exportações \\
Delmtxrate & Taxa de imposto sobre Importados \\
Delptxrate & Taxa de imposto sobre a produção \\
\hline
\end{tabular}

FONTE: Horridge (2003).

Cabe ressaltar que os resultados foram subdivididos por cada tipo de choque sendo que podemos individualizar a importância dos mesmos, como a seguir:

- Redução dos preços de têxteis = subtotal 1;

- Redução dos preços dos artigos de vestuário= subtotal 2;

- Aumento das tarifas de importação= subtotal 3;

O estoque de capital foi considerado fixo na simulação de curto prazo, pois admitimos que o mesmo não pode ser alterado rapidamente. $\mathrm{O}$ mercado de trabalho também é considerado rígido, mantendo-se os salários reais fixos.

As variáveis exógenas do $2^{\circ}$ choque de curto prazo foram as mesmas do $1^{\mathrm{o}}$ choque de curto prazo, todavia como o objetivo neste caso foi apenas de obter o valor das tarifas de importação que manteriam a variação da quantidade importada igual a zero, as tarifas de importação relativas a artigos de vestuário terão que ser fixas e, portanto, endógenas, enquanto que a quantidade importada de artigos de vestuário passa a ser exógena.

No fechamento de longo prazo, outras variáveis foram determinadas como exógenas, como mostra a Tabela 4.

TABELA 4. FECHAMENTO DA SIMULAÇÃO DE LONGO PRAZO

\begin{tabular}{ll}
\hline \multicolumn{1}{c}{ Variável } & \multicolumn{1}{c}{ Descrição } \\
\hline Phi & Taxa de Câmbio (R\$/US\$) \\
Employ & Emprego agregado \\
Gret & Taxa de retorno ao Capital \\
DelB & Balança comercial/PIB \\
X_s(COM, "Investment”) & Demanda por Investimento \\
X_s(COM,“Government") & Demanda do Governo \\
A1prim & Variação Técnica no Uso dos Fatores de \\
& Produção \\
Pworld & Preços Mundiais \\
F4q & Deslocador da Demanda por Exportações \\
Delmtxrate & Taxa de imposto sobre Importados \\
Delptxrate & Taxa de imposto sobre a produção \\
\hline
\end{tabular}

FONTE: Horridge (2003). 
No fechamento de longo prazo, o estoque de capital passa a ser endógeno (variável) e o que é mantido fixo é a taxa de retorno desse capital. O emprego agregado, (representado pela força de trabalho e taxa de desemprego) também é mantido fixo, ou seja, é determinado exogenamente e o salário real passa a ser variável (endógeno). Os preços mundiais também foram assumidos como exógenos, uma vez que os choques seriam dados nos mesmos e a balança comercial como fração do PIB variável continuou sendo exógena.

O consumo das famílias passou a ser exógeno, uma vez que no longo prazo os hábitos de consumo podem mudar, de acordo com alterações nos preços dos produtos ou na renda das famílias.

No que se refere à normalização, no modelo MINIMAL os valores resultantes expressam uma mudança em termos da magnitude do numerário. Especificamente neste trabalho, definiu-se o Índice de Preços ao Consumidor - IPC como o numerário, assim todas as variações resultantes do modelo estarão relacionadas à variação do IPC. Assim sendo, se o resultado para uma variável do modelo for de $1 \%$, a simulação indica que essa variável aumentará em 1\% acima da variação do IPC.

\section{Resultados}

Os resultados estão separados de acordo com os choques de curto e de longo prazo. Todas as análises foram feitas com base no software GEMPACK e os resultados encontrados para a simulação de curto prazo estão contidos nas Tabelas $5,6,7,8$ e 9 .

\subsection{Simulação de curto prazo}

Como já mencionado, na simulação de curto prazo foram implementados 3 choques: queda de $20 \%$ no preço mundial de têxteis, queda de $20 \%$ no preço mundial de artigos de vestuário e aumento de 17,8\% das tarifas de importação de artigos de vestuário.

A Tabela 5 contempla os principais resultados macroeconômicos para o choque de curto prazo. 
TABELA 5. RESULTADOS MACROECONÔMICOS DO CENÁRIO DE CURTO PRAZO PARA AS PRINCIPAIS VARIÁVEIS, EM VARIAÇÕES PERCENTUAIS.

\begin{tabular}{lcccc}
\hline \multicolumn{1}{|c}{ Variável } & $\begin{array}{c}\text { Efeito da } \\
\text { redução de } \\
\text { preços } \\
\text { (têxteis) }\end{array}$ & $\begin{array}{c}\text { Efeito da } \\
\text { redução de } \\
\text { preços } \\
\text { (artigos de } \\
\text { vestuário) }\end{array}$ & $\begin{array}{c}\text { Efeito do } \\
\text { aumento das } \\
\text { tarifas de } \\
\text { importação }\end{array}$ & $\begin{array}{c}\text { Variação } \\
\text { Total }\end{array}$ \\
\hline $\begin{array}{l}\text { Emprego } \\
\text { agregado }\end{array}$ & 0,148 & 0,005 & 0,004 & $\mathbf{0 , 1 5 7}$ \\
$\begin{array}{l}\text { Taxa de } \\
\text { salário }\end{array}$ & $-0,735$ & $-0,077$ & 0,068 & $\mathbf{- o , 7 4 3}$ \\
$\begin{array}{l}\text { Consumo } \\
\text { Real das }\end{array}$ & 0,14 & 0,016 & 0,008 & $\mathbf{0 , 1 6 3}$ \\
$\begin{array}{l}\text { Famílias } \\
\begin{array}{l}\text { PIB real } \\
\text { Indice de } \\
\text { preços de } \\
\text { exportação }\end{array}\end{array}$ & $-0,613$ & $-0,063$ & 0,07 & $\mathbf{- o , 6 0 6}$ \\
$\begin{array}{l}\text { Indice do } \\
\text { volume das } \\
\text { exportações }\end{array}$ & $-0,632$ & $-0,052$ & 0,051 & $\mathbf{- 0 , 6 3 3}$ \\
$\begin{array}{l}\text { Indice do } \\
\text { volume das } \\
\text { importações }\end{array}$ & 0,344 & 0,113 & $-0,048$ & $\mathbf{0 , 4 1}$ \\
\hline
\end{tabular}

FONTE: elaborado pelas autoras com base nos resultados da simulação

De maneira geral, o efeito da redução de preços atua em sentido contrário ao do aumento das tarifas, contudo, para o consumo real das famílias, o efeito é positivo para todos os choques. A redução do preço mundial provoca efeitos similares nas indústrias têxteis e de vestuário, porém estes efeitos são mais intensos no setor têxtil, mostrando que esse setor é mais vulnerável a variações externas de preços, uma vez que apresentam maior peso considerando têxteis e vestuário.

Quando o preço mundial é reduzido, há uma pressão pela redução de custos da indústria têxtil e de artigos de vestuário domésticas, provocando a redução da taxa de salário. Com preços menores a produção nacional aumenta impulsionada pelo aumento da exportação ${ }^{7}$ e do consumo das famílias.

A quantidade produzida aumenta, mas não consegue compensar a queda nos preços, como se pode observar com a queda do PIB real. A redução dos preços mundiais de têxteis e artigos de vestuário provocou uma queda do mesmo, que não foi compensada pelo efeito do aumento das tarifas (o,068\%). De fato, a redução dos preços mundiais interfere diretamente no PIB nacional, uma vez que o país passa a exportar produtos de menor valor. Percebe-se que o índice de preços de exportação teve uma queda de 0,633\%. Embora a 
exportação aumente em níveis percentuais (0.41\%), o aumento absoluto das importações é maior ${ }^{8}$.

Por outro lado, o efeito do aumento da tarifa de importação de artigos de vestuário encarece estes produtos importados, reduzindo suas importações. Estando o mercado interno protegido dos concorrentes externos, observa-se aumento dos preços domésticos e redução das exportações, como pode ser verificado na $3^{\mathrm{a}}$ coluna (de valores) da tabela 5 . O aumento do preço abre margem para o aumento na taxa de salário. Ao receber salários mais elevados, as famílias aumentam o consumo. O consumo interno supera a queda das exportações e o emprego agregado aumenta, mostrando que esse tipo de política gera impactos positivos na economia como um todo, assim como no setor de artigos de vestuário, o que pode ser verificado na Tabela 6 .

Como pode ser observado, considerando a variação total, ocorreu aumento do emprego agregado e do consumo real das famílias, apesar da queda na taxa de salários, na simulação de curto prazo. O PIB real apresentou queda, mesmo com o aumento das exportações. De fato, como já mencionado, embora as exportações tenham crescido a um percentual maior, em níveis absolutos a importação foi maior, causando um "déficit" da balança externa deste setor.

Além disso, como pode ser observado na Tabela 6, embora o emprego agregado tenha aumentado, houve uma redução desta variável no setor de têxteis, que foi compensada pelo aumento do emprego em outros setores. Assim sendo, o emprego agregado aumentou em $0,157 \%$, sendo em grande parte provocado pela redução dos preços mundiais de têxteis (0.148\%).

Por outro lado, houve uma redução na taxa de salário, o que de fato pode ser observado em praticamente todos os setores da economia brasileira a partir da década de 1990. A redução dos preços mundiais força a redução de custos, o que se concretiza através da redução real dos salários. O aumento das tarifas de importação provocaria um aumento modesto na taxa de salários, uma vez que reduziria a concorrência interna.

Com a queda nos preços eleva-se globalmente o consumo real das famílias (o,163\%), a maior parte sendo explicada pela redução dos preços de têxteis, que apresenta o maior peso dentre os setores analisados.

Na Tabela 6 é possível observar o comportamento de algumas variáveis nos setores agregados.

8 O aumento de $0,344 \%$ nas exportações gera R $\$ 4088$ mil, enquanto que o aumento de o,335\% nas importações corresponde a R \$ 8121,75 mil. 
TABELA 6 - CUSTO, PREÇO, PRODUÇÃO, EMPREGO E TAXA DE RETORNO DO CAPITAL POR INDÚSTRIA AGREGADA DA SIMULAÇÃO DE CURTO PRAZO, EM VARIAÇÕES PERCENTUAIS.

\begin{tabular}{|c|c|c|c|c|c|}
\hline $\begin{array}{l}\text { Indústrias } \\
\text { agregadas }\end{array}$ & Custo & Preço & Produção & Emprego & $\begin{array}{c}\text { Taxa de } \\
\text { Retorno } \\
\text { do } \\
\text { capital }\end{array}$ \\
\hline Agropecuária & $-0,32$ & $-0,32$ & 0,02 & 0,15 & 0,48 \\
\hline Mineração & $-0,3$ & $-0,3$ & 0,25 & 0,75 & 1,3 \\
\hline Manufatura & $-0,57$ & $-0,57$ & 0,25 & 0,5 & 0,25 \\
\hline Capital Fzxo & $-0,54$ & $-0,54$ & 0,16 & 0,39 & 0,16 \\
\hline $\begin{array}{l}\text { Indústria } \\
\text { Química }\end{array}$ & $-0,52$ & $-0,52$ & 0,1 & 0,27 & 0,06 \\
\hline $\begin{array}{l}\text { Indústria } \\
\text { Têxtil }\end{array}$ & $-6,9$ & $-6,9$ & $-6,79$ & $-19,16$ & $-15,66$ \\
\hline $\begin{array}{c}\text { Artigos de } \\
\text { Vestuário }\end{array}$ & $-4,09$ & $-4,09$ & 3,23 & 3,5 & 2,61 \\
\hline $\begin{array}{c}\text { Refino de } \\
\text { Petróleo }\end{array}$ & $-0,4$ & $-0,4$ & 0,05 & 0,38 & 0,15 \\
\hline Agroindústria & $-0,53$ & $-0,53$ & 0,1 & 0,24 & 0,06 \\
\hline $\begin{array}{l}\text { Comércio e } \\
\text { Transporte }\end{array}$ & $-0,66$ & $-0,66$ & 0,25 & 0,3 & 0,03 \\
\hline $\begin{array}{c}\text { Construção } \\
\text { Civil }\end{array}$ & $-0,67$ & $-0,67$ & 0,01 & 0,03 & $-0,13$ \\
\hline Serviços & $-0,7$ & $-0,7$ & 0,09 & 0,15 & $-0,03$ \\
\hline
\end{tabular}

FONTE: elaborado pelas autoras com base nos resultados da simulação

A queda dos preços mundiais não gera um cenário mais recessivo porque a participação desses setores na economia é relativamente reduzida, com pouco mais de $2 \%$ do PIB. A redução dos preços é verificada em todos os setores sendo os mais afetados aqueles que mais utilizam produtos têxteis, ou seja, o próprio setor têxtil e de vestuário.

Observa-se que a redução provocada no custo de cada setor é idêntica à redução observada nos preços, contudo, a indústria têxtil e a de artigos de vestuário presenciaram as maiores quedas, de 6,9\% e 4,09\%, respectivamente. Embora não esteja explícito na tabela, o aumento das tarifas atua em sentido contrário, provocando aumento de custo e preços, entretanto, não sendo suficiente para neutralizar a queda de preços.

Como a indústria têxtil serve de insumo para grande parte das indústrias, quando o preço dos produtos têxteis é reduzido, o custo dos outros setores também diminui, gerando um aumento na demanda, na produção e na geração de emprego agregado. Estes impactos positivos gerados nos outros setores acabam por compensar os danos gerados, sobretudo na indústria têxtil, que ainda é proporcionalmente pequena no Brasil.

A produção aumentaria em todos os setores, exceto na indústria têxtil, cuja queda observada seria de 6,79\%. Obviamente, a entrada de artigos têxteis a 
preços mais baixos prejudica a produção nacional para esta indústria, que passa a enfrentar uma competição mais acirrada dos produtos chineses, principalmente. O emprego neste setor cairia drasticamente (-19,16\%), assim como a taxa de retorno do capital (-15,66\%). Em síntese, o setor de têxtil foi o mais severamente penalizado pela queda de preços mundiais, sendo que o aumento das tarifas sobre a importação de artigos de vestuário não seria suficiente para compensar estes efeitos.

Contudo, os efeitos nestes setores não seriam suficientes para causar um efeito no emprego agregado 9 , conforme pode ser observado na Tabela 5. Por outro lado, seria observada uma queda do PIB real, em consequência, além dos fatores já mencionados, da redução de empregos no setor têxtil e de vestuário e redução dos preços de exportação.

De fato, embora o setor têxtil tenha sido penalizado, o setor de vestuário foi favorecido, tanto pela queda de preços da matéria-prima quanto pelo aumento das tarifas. Com a queda de preços de sua matéria-prima reduziu-se o custo para esta indústria, gerando resultados positivos, observados pelo aumento da produção, emprego e do retorno de capital. Os demais setores também seguiram esta tendência.

Embora o aumento das tarifas seja uma medida favorável ao setor de vestuário, cabe ressaltar que o aumento de preços acaba afetando diretamente os consumidores. Segundo a Abeim - Associação Brasileira do Varejo Têxtil (2007), que reúne sete grandes redes varejistas (Renner, Marisa, C\&A, WalMart, Mango, Cori e Luigi Bertolli), o aumento do imposto de importação para têxteis possivelmente irá elevar o preço dos produtos para o consumidor no Brasil, uma vez que importam entre $8 \%$ e $10 \%$ de seus itens, principalmente casacos, tricôs e peças de tecido sintético.

Em 2006 o Brasil importou 3,4\% de seu consumo total, o que representa 37 mil toneladas e US $\$ 347$ milhões. A participação dos importados no setor, embora não seja alta, cresceu muito nos últimos anos. Em 2005 esse índice era de $3 \%$, em 2004, de 2,7\% e, em 2003, de 1,3\%. Em valores, os importados representaram em 2006 1,4\% da receita do setor, exatamente o dobro do registrado em 2003, 0,7\%.

$\mathrm{O}$ resultado da $2^{\mathrm{a}}$ simulação de curto prazo indicou que a tarifa deveria sofrer um aumento de $26 \%$ para que a variação na quantidade importada de artigos de vestuário permanecesse igual a zero, ou seja, para que não houvesse um aumento das importações de forma a aumentar a concorrência com os produtos nacionais. Assim sendo, nota-se que o aumento de tarifas adotado pelo governo brasileiro, de $20 \%$ para $35 \%$, ainda é insuficiente para proteger a indústria nacional. Para manter constante a quantidade importada esse aumento deveria ser de $43,2 \%$, entretanto, por questões legais, isto não é factível, uma vez que o teto tarifário brasileiro para produtos industrializados na OMC é de 35\% (FONTE).

9 A redução do emprego no setor têxtil é muito elevada (-19\%), porém pouco significativa em relação às demais atividades, por isso acaba sendo compensada pelo aumento gerado nos outros setores. 
Além disso, embora a indústria de confecção no Brasil empregue cerca de 1,5 milhões de pessoas, medidas protecionistas poderiam prejudicar o consumidor final, devido ao aumento de preços. Cabe ressaltar que isoladamente o aumento das tarifas não seria suficiente para conter os baixos preços praticados, sobretudo pela China e Índia.

\subsection{Simulação de Longo Prazo}

Vale lembrar que para o cenário de longo prazo, o fechamento foi modificado, sendo que na determinação das variáveis exógenas, o salário real substituiu o emprego, a taxa de retorno do capital foi substituída por estoque de capital e assim como no choque de curto prazo, o consumo real das famílias substituiu a relação Balança Comercial/PIB.

Nesta simulação, o choque foi dado conforme o primeiro choque de curto prazo, ou seja, uma queda de $20 \%$ nos preços mundiais de têxteis e de artigos de vestuário associado com um aumento de 17,8\% das tarifas de importação de artigos de vestuário. Os principais resultados macroeconômicos podem ser observados na Tabela 7.

TABELA 7. RESULTADOS MACROECONÔMICOS DO CENÁRIO DE LONGO PRAZO PARA AS PRINCIPAIS VARIÁVEIS, EM VARIAÇÕES PERCENTUAIS.

\begin{tabular}{lcccc}
\hline \multicolumn{1}{c}{ Variável } & $\begin{array}{c}\text { Efeito da } \\
\text { redução de } \\
\text { preços } \\
\text { (têxteis) }\end{array}$ & $\begin{array}{c}\text { Efeito da } \\
\text { redução de } \\
\text { preços } \\
\text { (artigos de } \\
\text { vestuário) }\end{array}$ & $\begin{array}{c}\text { Efeito do } \\
\text { aumento das } \\
\text { tarifas de } \\
\text { importação }\end{array}$ & $\begin{array}{c}\text { Variação } \\
\text { Total }\end{array}$ \\
\hline $\begin{array}{l}\text { Salário Real } \\
\text { Indice de } \\
\text { preços ao }\end{array}$ & $-0,03$ & 0 & 0,01 & $-0,03$ \\
$\begin{array}{l}\text { consumidor } \\
\begin{array}{l}\text { Consumo } \\
\text { real das }\end{array}\end{array}$ & $-0,65$ & $-0,07$ & 0,07 & $-0,66$ \\
$\begin{array}{l}\text { famílias } \\
\text { PIB real }\end{array}$ & $-0,16$ & 0 & 0,02 & $-0,14$ \\
$\begin{array}{l}\text { Índice de } \\
\text { preços de } \\
\text { exportação }\end{array}$ & $-0,71$ & $-0,06$ & 0,07 & $-0,7$ \\
$\begin{array}{l}\text { Indice do } \\
\text { volume das } \\
\text { exportações }\end{array}$ & $-0,61$ & $-0,05$ & 0,05 & $-0,6$ \\
$\begin{array}{l}\text { Indice do } \\
\text { volume das } \\
\text { importações }\end{array}$ & 0,31 & 0,11 & $-0,05$ & 0,38 \\
\hline
\end{tabular}

FONTE: elaborado pelas autoras com base nos resultados da simulação 
Assim como no curto prazo, a redução dos preços de têxteis é que teve maior interferência no resultado global devido, sobretudo, ao maior peso deste setor.

Ao contrário do que foi observado no cenário de curto prazo, no choque de longo prazo, o consumo real das famílias sofre uma redução de o,14\% devido, em partes, à queda no salário real (-0,03\%) provocada sobretudo pelo efeito da redução dos preços de têxteis. $\mathrm{O}$ aumento das tarifas de importação de artigos de vestuário atua em sentido contrário, porém não foi suficiente para superar o efeito negativo.

Embora haja um aumento do volume das exportações (o,38\%), as importações também aumentariam (o,25\%). Entretanto, com a queda no índice de preços de exportação, seria observada uma queda do PIB real (-0,7\%). Assim como no choque de curto prazo, embora haja um aumento percentual maior das exportações, em valor, as importações foram maiores, gerando um déficit na balança externa, o que contribuiu para queda do PIB real.

TABELA 8. CUSTO, PREÇO, PRODUÇÃO, EMPREGO SETORIAL, ESTOQUE DE CAPITAL CORRENTE E DEMANDA TOTAL POR INDÚSTRIA AGREGADA DA SIMULAÇÃO DE LONGO PRAZO, EM VARIAÇÕES PERCENTUAIS.

\begin{tabular}{|c|c|c|c|c|c|}
\hline $\begin{array}{l}\text { Indústrias } \\
\text { agregadas }\end{array}$ & Custo & $\begin{array}{c}\text { Preço } \\
\text { Doméstico }\end{array}$ & Produção & $\begin{array}{c}\text { Emprego } \\
\text { setorial }\end{array}$ & $\begin{array}{c}\text { Estoque } \\
\text { de } \\
\text { capital } \\
\text { corrente }\end{array}$ \\
\hline Agropecuária & $-0,55$ & $-0,55$ & $-0,01$ & 0,02 & $-0,02$ \\
\hline Mineração & $-0,54$ & $-0,54$ & 0,25 & 0,31 & 0,22 \\
\hline Manufatura & $-0,56$ & $-0,56$ & 0,12 & 0,23 & 0,02 \\
\hline Capital Füxo & $-0,54$ & $-0,54$ & 0,04 & 0,17 & $-0,04$ \\
\hline $\begin{array}{l}\text { Indústria } \\
\text { Química }\end{array}$ & $-0,51$ & $-0,51$ & $-0,09$ & 0,04 & $-0,17$ \\
\hline $\begin{array}{l}\text { Indústria } \\
\text { Têxtil }\end{array}$ & $-3,33$ & $-3,33$ & $-10,53$ & $-10,41$ & $-10,59$ \\
\hline $\begin{array}{c}\text { Artigos de } \\
\text { Vestuário }\end{array}$ & $-2,54$ & $-2,54$ & 1,39 & 1,4 & 1,19 \\
\hline $\begin{array}{c}\text { Refino de } \\
\text { Petróleo }\end{array}$ & $-0,45$ & $-0,45$ & $-0,22$ & $-0,04$ & $-0,25$ \\
\hline Agroindústria & $-0,58$ & $-0,58$ & $-0,02$ & 0,09 & $-0,1$ \\
\hline $\begin{array}{l}\text { Comércio e } \\
\text { Transporte }\end{array}$ & $-0,61$ & $-0,61$ & 0,01 & 0,05 & $-0,23$ \\
\hline $\begin{array}{c}\text { Construção } \\
\text { Civil }\end{array}$ & $-0,55$ & $-0,55$ & $-0,01$ & 0,18 & $-0,05$ \\
\hline Serviços & $-0,62$ & $-0,62$ & $-0,1$ & $-0,01$ & $-0,22$ \\
\hline
\end{tabular}

FONTE: elaborado pelas autoras com base nos resultados da simulação de longo prazo 
Como pode ser observado na Tabela 8 , tanto o custo quanto o preço sofreriam uma queda em todos os setores, sendo que a queda de preço seria da mesma proporção da redução do custo. As maiores reduções se dariam, obviamente, no setor têxtil (3,33\%) e no de artigos de vestuário (2,54\%).

Este preço refere-se ao preço doméstico, contudo, quando se trata do preço importado, cabendo ressaltar que a queda de preço de artigos de vestuário não seria de $20 \%$ como foi dado no choque, uma vez que o aumento das tarifas de importação de vestuário agiria em sentido contrário, resultando em uma queda final do preço de artigos de vestuário de 7,4\% (Tabela 10- Anexo A).

Relativo à produção, o resultado é bastante variável, sendo que alguns setores passariam por aumento da produção e outros por retração. A indústria têxtil presenciaria uma queda drástica de 10,53\%, contudo, o setor de artigos de vestuário aumentaria sua produção, uma vez que teria seu custo reduzido pela queda de preços de sua principal matéria-prima.

Contudo, o setor têxtil enfrentaria a concorrência dos produtos importados, reduzindo sua produção e também o emprego no setor, que sofreria queda significativa de $10,41 \%$. Os setores de serviços e de refino de petróleo também observariam uma retração do emprego, embora em proporções menores.

TABELA 9. DEMANDA DOMÉSTICA E IMPORTADA, POR SETOR, DA SIMULAÇÃO DE LONGO PRAZO, EM VARIAÇÕES PERCENTUAIS.

\begin{tabular}{ccc}
\hline Indústrias agregadas & Demanda doméstica & Demanda Importada \\
\hline Agropecuária & $-0,01$ & $-1,07$ \\
Mineração & 0,25 & $-0,41$ \\
Manufatura & 0,12 & $-0,95$ \\
Capital Fïo & 0,04 & $-0,42$ \\
Indústria Química & $-0,09$ & $-0,63$ \\
Indústria Têxtil & $-10,53$ & 36,36 \\
Artigos de Vestuário & 1,39 & 13,57 \\
Refino de Petróleo & $-0,22$ & $-0,69$ \\
Agroindústria & $-0,02$ & $-1,21$ \\
Comércio e Transporte & 0,01 & -1 \\
Construção Civil & $-0,01$ & $-0,68$ \\
Serviços & $-0,1$ & $-0,79$ \\
\hline
\end{tabular}

FONTE: elaborado pelas autoras com base nos resultados da simulação de longo prazo

Conforme pode ser observado na Tabela 9, a demanda por produtos têxteis domésticos no longo prazo sofre redução $(-10,53 \%)$, enquanto que a demanda por produtos têxteis importados aumenta (36,36\%), ou seja, no longo prazo o setor não consegue acompanhar a queda dos preços mundiais e perde mercado para os produtos importados.

O mesmo não ocorre com a indústria de artigo de vestuário, tanto a deman- 
da por produtos domésticos como importados aumenta, porém a demanda por produtos importados aumenta cerca de 10 vezes mais que a demanda por produtos domésticos. Esse setor é beneficiado pela queda de preços dos produtos têxteis, o qual representa, aproximadamente, $77 \%$ dos seus custos.

A queda da demanda por produtos agropecuários é reduzida, provavelmente, pela queda da demanda interna por produtos têxteis, utilizando-se, principalmente, o algodão como matéria-prima, o mesmo ocorrendo com o refino de petróleo, a agroindústria e a construção civil que sofrem também com a queda no PIB.

\section{Considerações Finais}

O aumento dos impostos de importação dos setores têxteis e de vestuários proposto pelo governo em 2007 não foi suficiente para compensar os efeitos econômicos causados pela queda nos preços mundiais devido à liberalização comercial da década de noventa.

Com a queda de preços mundiais de têxteis e artigos de vestuário o setor mais penalizado foi o de têxteis, que apresentou queda acentuada da produção e dos empregos. De fato, a indústria têxtil nacional vivenciou um período de fechamento de muitas empresas, desde a abertura comercial realizada na década de 1990.

Ressalta-se ainda que modelos de ECG são substancialmente sensíveis aos pressupostos adotados. Como a elasticidade da demanda para o setor têxtil é bastante superior, é esperado que as variações dos preços mundiais afetem de forma mais intensa este setor que o setor de vestuário.

O setor de vestuário, apesar da queda de preços, apresentou redução do custo e aumento da produção, com consequente aumento da taxa de retorno de capital, tendo sido, portanto, beneficiada no curto prazo, tanto pela queda de preços mundiais quanto pela política de aumento de tarifas de importação.

Apesar desses efeitos, no curto prazo a queda de preços mundiais de têxteis e artigos de vestuário provocou na economia como um todo redução de custos, com consequente aumento de produção, exportações e geração de empregos, apesar da drástica queda vivenciada pelo setor têxtil. Ainda assim, foi observada queda do PIB real, devido à queda no valor das exportações e aumento maior das importações em valores absolutos.

Embora no curto prazo os efeitos tenham sido positivos, no longo prazo o efeito para a economia brasileira não foi benéfico, uma vez que há queda real nos salários, queda no consumo das famílias, das exportações e do PIB real, caracterizando uma perda de bem-estar. Adicionalmente se o emprego agregado fosse endógeno no modelo, possivelmente haveria retração também 
desta variável.

Uma análise geral leva a crer que o setor têxtil deveria ser mais protegido que o setor de vestuário, embora o consumidor final possa ser prejudicado com este tipo de política protecionista. Todavia, com os resultados desfavoráveis obtidos no cenário de longo prazo as conclusões são análogas aos argumentos favoráveis ao livre comércio observados em Krugman e Obstfeld (2005), ou seja, apesar de no curto prazo a implantação de um tarifa de importação trazer resultados positivos ela tem que estar aliada a outras políticas, como de modernização industrial para que no longo prazo se torne competitiva a nível mundial e traga resultados econômicos positivos.

Cabe mencionar que a análise dos resultados apresentados possui algumas limitações, como restrição do número de parâmetros a serem estimados e adoção de pressupostos a respeito do comportamento dos agentes produtores e consumidores. Além disso, nesta simulação, cada indústria conta apenas como uma empresa, não tendo como estimar a quebra das pequenas empresas provocada pela redução dos preços mundiais, o que pode gerar efeitos ainda mais drásticos do que o observado com o programa. Ainda assim, podemos obter resultados interessantes, uma vez que estamos analisando impactos da abertura comercial ocorrida na década de 90.

\section{Referências}

ANNABI, N. \& KHONDKER, B. \& RAIHAN, S. \& COCKBURN, J. E. \& DECALUWE, B. (2005). Chapter 15 in Putting Development Back into the Doha Agenda: Poverty Impacts of a WTO Agreement, Thomas W. Hertel and L. Alan Winters (eds.) forthcoming from the World Bank, Washington, DC.

. (2007). Brasil têxtil 2007. Relatório Setorial da Indústria Têxtil Brasileira. São Paulo.

BROWN, D. K. \& DEARDOFF, A. V. \& STERN, R. (1994). Estimates of a North American free trade agreement. Mineápolis: Federal Reserve Bank of Minneapolis, Manuscript.

CAMPOS, M. J. C. \& CAMPOS, L. H. R. (2004). Competitividade do Setor Têxtil Brasileiro: uma abordagem a nível estadual.

CAVALCANTE, J. \& MERCENIER, J. (1999). Uma avaliação dos ganhos dinâmicos do Mercosul usando equilíbrio geral. Pesq. Plan. Econ., Rio de Janeiro, 29(2):153-184.

CNI/ABIT - CONFEDERAÇÃO NACIONAL DA INDÚSTRIA/ ASSOCIAÇÃO BRASILEIRA DA INDÚSTRIA TÊXTIL E CONFECÇÃO. (2000). Estudos setoriais para subsidiar as negociações de acesso a mercados: a cadeia têxtil, relatório final. Brasília, DF: CNI, Rio de Janeiro: Funcex. 
DOMINGUES, E. P. (2002). Dimensão regional e setorial da integração brasileira na Área de Livre Comércio das Américas. 2002. Tese (Doutorado) - Faculdade de Economia, Administração e Contabilidade - Universidade de São Paulo, São Paulo.

DOMINGUES, E. P. \& HADDAD, E. A. (2006). Impactos setoriais e regionais da Alca: projeções para a economia brasileira. Pesquisa e planejamento econômico (PPE) 256, 36(2).

FERREIRA FILHO, J.B.S. (2006). Introdução aos Modelos de Equilíbrio Geral: Conceitos, Teoria e Aplicações. Piracicaba: Escola Superior de Agricultura "Luiz de Queiroz", URL: http://www.economia.esalq.usp.br/ jbsferre.

GORINI, A P. F. (2000). Panorama do setor têxtil noBrasil e no mundo: reestruturação e perspectivas. Fórum de Competitividade do Ministério do Desenvolvimento, Indústria e Comércio Exterior, BNDES Setorial, Rio de Janeiro, 12:17-50.

GURGEL, A.C. \& CAMPOS, A.C. (2006). A avaliação de políticas comerciais em modelos de equilíbrio geral com pressuposições alternativas quanto aos retornos de escala. Est. econ., São Paulo, 36(2): 323-354.

HASEGAWA, M.M. \& FACHINELLO, A. \& SANTOS, C.V. \& FERREIRA FILHO, J.B.S. (2001). MINIMAL: Um Modelo Simplificado de Equilíbrio Geral para a Economia Brasileira. URL: www.economia.esalq.usp.br/ arlei. Tradução de novembro de 2006 da Edição de Horridge, M., A Simplified General Equilibrium Model, Centre of Policy Studies and the Impact Project, Monash University, Wellington Road, Clayton, Victoria, Austrália. URL: http://www. monash.edu.au/policy

HORRIDGE, M. (2003). Minimal: Um Modelo simplificado de Equilíbrio Geral. Piracicaba: (mimeo). Traduzido por Cárlinton Vieira e Marcos Minoru Hasegawa \& Revisão Técnica de Joaquim Bento de Souza Ferreira Filho.

IEMI - Instituto de Estudos e Marketing Industrial S/C Ltda. (2001). Primeiro Relatório do Setor Têxtil Brasileiro. São Paulo.

IEMI - Instituto de Estudos e Marketing Industrial S/C Ltda. (2007). Primeiro Relatório do Setor Têxtil Brasileiro. São Paulo.

IEMI - Instituto de Estudos e Marketing Industrial S/C Ltda. (2008). Primeiro Relatório do Setor Têxtil Brasileiro. São Paulo.

IPEADATA. (2008). Base de Dados Macroeconômicos. Instituto de Pesquisa Econômica Aplicada - IPEA. URL: <http://www.ipeadata.gov.br>. Acesso em: 30 ago. 2008.

MORELLI, E. C. (2008). Novas tendências de importação no mercado brasileiro. Swisscam Magazine. São Paulo, 51:18-19. URL: <http:www.swisscam.com. br/files_revista/28_51_econom_brasileira.pdf>. Acesso em: 30 ago. 2008.

PROCHNIK, V. (2003). A cadeia têxtil/confecções perante os desafios da Alca e do acordo comercial com a União Européia. ECONOMIA, Niterói (RJ), 4(1):53-83.

TOURINHO, O. A. F. \& KUME, H. \& PEDROSO, A. C. S. (2003). Elasticidades de Armington para o Brasil 1986-2002. Novas estimativas. Rio de Janeiro: IPEA, Texto para a Discussão n. 974. 
Recebido em: 23 de março de 2009 Primeira resposta em: 15 de junho de 2009 Aceite em: 07 de outubro de 2009

\section{ANEXO A}

TABELA 10. PREÇOS DOMÉSTICOS E IMPORTADOS NA SIMULAÇÃO DE LONGO PRAZO.

\begin{tabular}{ccc}
\hline Indústrias agregadas & Preço Doméstico & Preço Importado* $^{*}$ \\
\hline Agropecuária & -0.55 & 0 \\
Mineração & -0.54 & 0 \\
Manufatura & -0.56 & 0 \\
Capital Füxo & -0.54 & 0 \\
Indústria Química & -0.51 & 0 \\
Indústria Têxtil & -3.33 & -20 \\
Artigos de Vestuário & -2.54 & -7.4 \\
Refino de Petróleo & -0.45 & 0 \\
Agroindústria & -0.58 & 0 \\
Comércio e Transporte & -0.61 & 0 \\
Construção Civil & -0.55 & 0 \\
Serviços & -0.62 & 0 \\
\hline
\end{tabular}

FONTE: elaborado pelas autoras com base nos resultados da simulação de longo prazo

*Obs: O preço dos bens importados de outros setores, como agropecuária, são exógenos, portanto igual a zero, porque nenhum outro valor lhes foi estipulado. 
